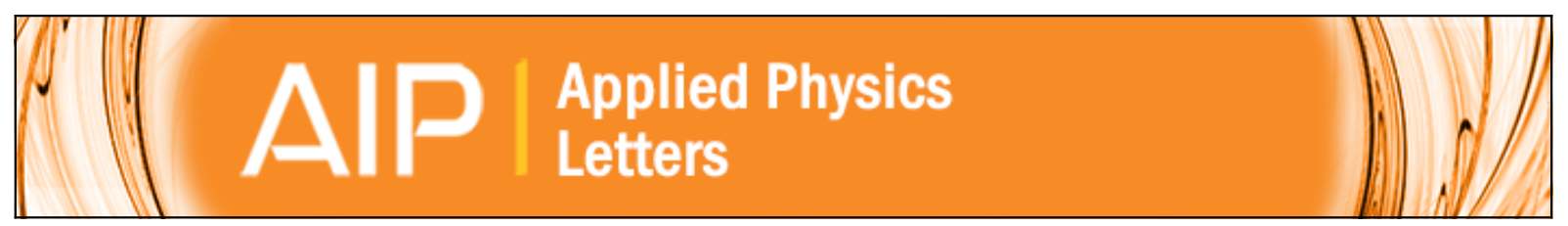

\title{
Hydrogen interstitial defects in acceptor-type CuO-doped PbTiO3-Uptake and dissolution of water vapor and formation of (CuTi"-(OH)O•)' defect complexes
}

Peter Jakes, Hans Kungl, Roland Schierholz, Josef Granwehr, and Rüdiger-A. Eichel

Citation: Applied Physics Letters 109, 122904 (2016); doi: 10.1063/1.4962816

View online: http://dx.doi.org/10.1063/1.4962816

View Table of Contents: http://scitation.aip.org/content/aip/journal/apl/109/12?ver=pdfcov

Published by the AIP Publishing

\section{Articles you may be interested in}

Tuning the formation of $p$-type defects by peroxidation of CuAlO2 films

J. Appl. Phys. 114, 033712 (2013); 10.1063/1.4816044

Interactions of defect complexes and domain walls in $\mathrm{CuO}$-doped ferroelectric $(\mathrm{K}, \mathrm{Na}) \mathrm{NbO} 3$

Appl. Phys. Lett. 102, 242908 (2013); 10.1063/1.4811268

Native p-type transparent conductive Cul via intrinsic defects

J. Appl. Phys. 110, 054907 (2011); 10.1063/1.3633220

Modeling the polaronic nature of $\mathrm{p}$-type defects in $\mathrm{Cu} 2 \mathrm{O}$ : The failure of GGA and GGA + $U$

J. Chem. Phys. 131, 124703 (2009); 10.1063/1.3231869

Effects of the $\mathrm{MnO}$ additives on the properties of $\mathrm{Pb}$ ( $\mathrm{Fe} 2 / 3 \mathrm{~W} 1 / 3$ ) - $\mathrm{Pb}$ Ti O 3 relaxors: Comparison of empirical law and experimental results

J. Appl. Phys. 101, 054117 (2007); 10.1063/1.2709876

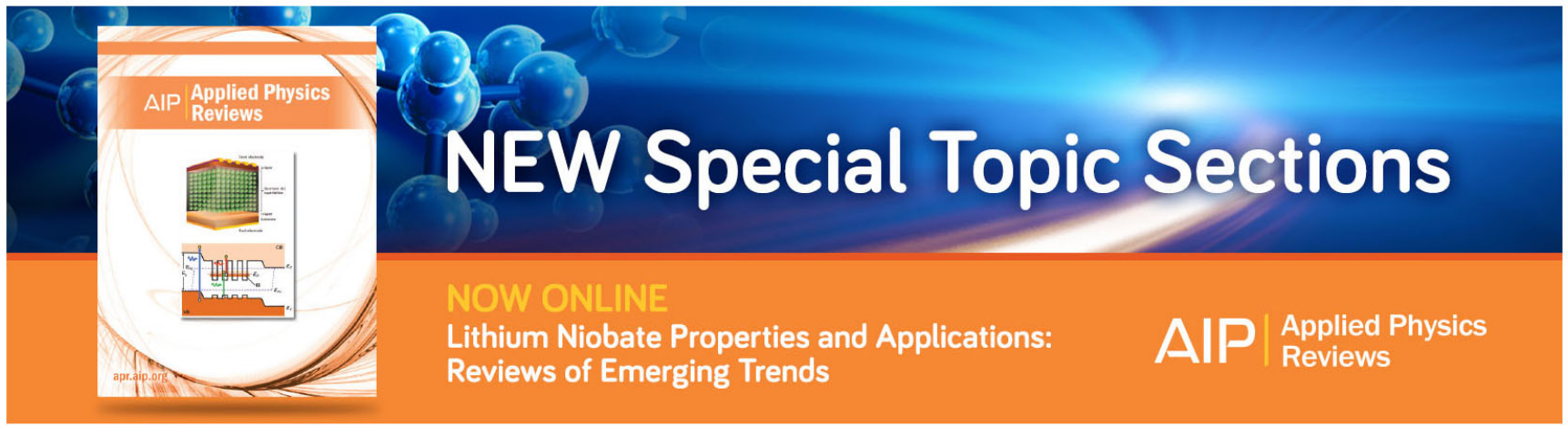




\title{
Hydrogen interstitial defects in acceptor-type CuO-doped $\mathrm{PbTiO}_{3}$-Uptake and dissolution of water vapor and formation of $\left(\mathrm{Cu}_{\mathrm{Ti}_{\mathrm{i}}^{\prime}}^{\prime \prime}-(\mathrm{OH})_{\mathrm{O}}^{\circ}\right)^{\prime}$ defect complexes
}

\author{
Peter Jakes, ${ }^{1}$ Hans Kungl, ${ }^{1}$ Roland Schierholz, ${ }^{1}$ Josef Granwehr, ${ }^{1,2}$ \\ and Rüdiger-A. Eichel ${ }^{1,3, a)}$ \\ ${ }^{1}$ Forschungszentrum Jülich, Institut für Energie-und Klimaforschung (IEK-9), D-52425 Jülich, Germany \\ ${ }^{2}$ Institut für Technische und Makromolekulare Chemie, RWTH Aachen University, D-52074 Aachen, Germany \\ ${ }^{3}$ Institut für Physikalische Chemie, RWTH Aachen University, D-52074 Aachen, Germany
}

(Received 2 June 2016; accepted 2 September 2016; published online 22 September 2016)

\begin{abstract}
The defect structure of $\mathrm{CuO}$-doped $\mathrm{PbTiO}_{3}$ has been analyzed using the Hyperfine Sublevel Correlation Experiment to identify hydrogen interstitials. The formation of $\left(\mathrm{Cu}_{\mathrm{Ti}}^{\prime \prime}-(\mathrm{OH})_{\mathrm{O}}^{*}\right)^{\prime}$ defect complexes has been observed, which exist in addition to the $\left(\mathrm{Cu}_{\mathrm{Ti}}^{\prime \prime}-V_{\mathrm{O}}^{* \bullet}\right)^{\times}$complexes. On this basis, modified reorientation characteristics are proposed due to a change in hopping mechanism from an oxygen-vacancy mediated migration mechanism to a proton hopping process. Furthermore, mobile hydrogen interstitials are generated that increase conductivity in terms of a "Grotthuss"-type charge-transport mechanism. Published by AIP Publishing.

[http://dx.doi.org/10.1063/1.4962816]
\end{abstract}

Ferroelectric devices based on lead zirconate titanate $\left(\mathrm{Pb}\left[\mathrm{Zr}_{x} \mathrm{Ti}_{1-x}\right] \mathrm{O}_{3}, \mathrm{PZT}\right)$ range from thin-film non-volatile memory applications (ferroelectric random-access memory) to "bulk" piezoelectric actuators or multilayer capacitors. Across the various fields of application, a primary issue is the incorporation of atomistic defects during processing that may lead to device degradation. ${ }^{1,2}$ Gaining insight into the defect structure is thus an essential step to develop strategies for improved materials and to prevent materials degradation.

Hydrogen-related defects represent a class of defects of particular interest. For $\mathrm{PbTiO}_{3}$, the existence of interstitial hydrogen defects has been predicted based on "ab-initio" calculations. ${ }^{3}$ Their impact on device degradation is mainly twofold: first, thin-film devices are typically subjected to a forming-gas anneal during fabrication in order to passivate the interface defects. This anneal injects hydrogen, leading to a loss of switchable polarization. ${ }^{4-6}$ Second, in devices fabricated from "bulk" piezoelectrics that are processed under ambient atmosphere, humidity can increase the leakage current, inducing an insulator-semiconductor transition. ${ }^{7-11}$

To investigate the interplay between hydrogen-related defects and defects resulting from aliovalent acceptor doping, $\mathrm{CuO}$-doped $\mathrm{PbTiO}_{3}$ has been investigated. As a sensitive spectroscopic tool, electron paramagnetic resonance (EPR) has already been providing detailed information, ${ }^{12,13}$ in particular, on the defect structure at the first coordination sphere. ${ }^{14-18}$ By employing the pulsed hyperfine sublevel correlation experiment (HYSCORE), also magnetically active nuclei at more distant coordination spheres may be probed. ${ }^{19,20}$

$0.25 \mathrm{~mol} \% \mathrm{CuO}$-doped $\mathrm{PbTiO}_{3}$ powders were prepared by a standard mixed-oxide route, ${ }^{20}$ where calcination was performed at $850^{\circ} \mathrm{C}$ for 2 hours, starting from ambient atmosphere, i.e. humid conditions to a certain extent.

\footnotetext{
${ }^{\text {a) }}$ Author to whom correspondence should be addressed. Electronic mail: r.eichel@fz-juelich.de
}

The X-band pulse EPR measurements were performed at $9.7 \mathrm{GHz}$ on a Bruker ElexSys 680 spectrometer at a temperature of $10 \mathrm{~K}$. The field-swept free induction decay (FID) induced EPR spectrum was obtained using highly selective microwave pulses of $500 \mathrm{~ns}$ duration. HYSCORE spectra were recorded using a standard four-pulse sequence $\left(\frac{\pi}{2}-\tau-\frac{\pi}{2}\right.$ $-t_{1}-\pi-t_{2}-\frac{\pi}{2}-\tau-$ echo) and an eight-step phase cycle. ${ }^{21}$ Pulse lengths of $t_{\pi / 2}=t_{\pi}=16 \mathrm{~ns}$ and a delay time of $\tau=240 \mathrm{~ns}$ were employed.

The theoretical description of EPR and HYSCORE spectra for an unpaired $3 d^{9}$ electronic configuration with spin $S=\frac{1}{2}$, as representative for $\mathrm{Cu}^{2+}$, interacting with a nuclear spin $I=\frac{1}{2}$ such as ${ }^{1} \mathrm{H}$, is based on the spin Hamiltonian

$$
\mathcal{H}=\beta_{e} \mathbf{B}_{0} \cdot \mathbf{g} \cdot \mathbf{S}-\beta_{n} g_{n} \mathbf{B}_{0} \cdot \mathbf{I}+h \mathbf{S} \cdot \mathbf{A} \cdot \mathbf{I},
$$

where $g_{n}$ is the nuclear $g$-factor, and $\beta_{e}, \beta_{n}$ are the Bohr and nuclear magneton, respectively, and $h$ is Planck's constant. The first and second term are the electronic and nuclear Zeeman interaction, respectively, where $\mathbf{B}_{0}$ denotes the

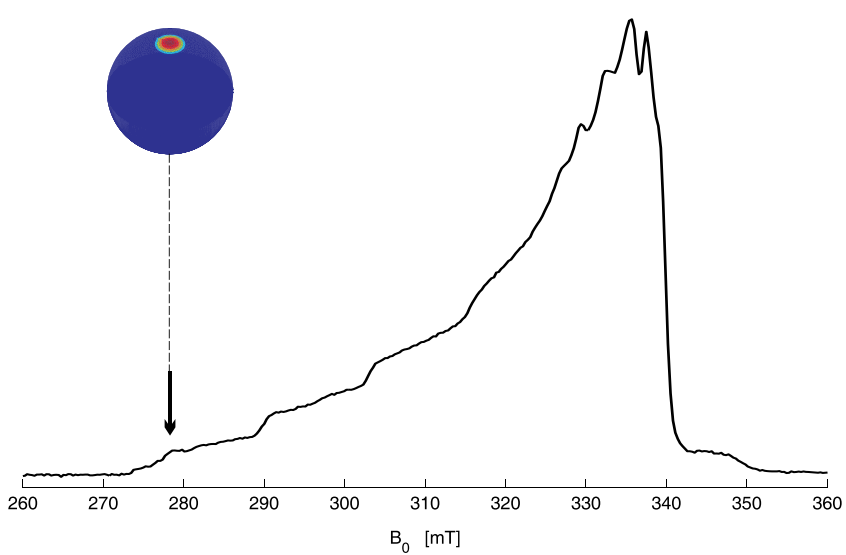

FIG. 1. FID-detected X-band EPR spectrum of $0.25 \mathrm{~mol} \% \mathrm{CuO}$-doped $\mathrm{PbTiO}_{3}$ recorded at $10 \mathrm{~K}$. ${ }^{19}$ The orientation-selective observer position for ${ }^{1} \mathrm{H}-\mathrm{HYSCORE}$ is indicated by an arrow. 
external magnetic field. The last term corresponds to the hyperfine interaction with a nearby magnetic nucleus. The hyperfine tensor $\mathbf{A}$ as well as the external field $\mathbf{B}_{0}$ are given in the principal axes system of the g-matrix of the electron spin. The copper nuclear quadrupole interaction was not resolved in the EPR spectra (cf. Figure 1) and thus has been neglected.

The hyperfine interaction A can generally be expressed as $\mathbf{A}=a_{\text {iso }}+\mathbf{A}^{\prime}$, where $a_{\text {iso }}$ is the isotropic hyperfine coupling constant, and the tensor $\mathbf{A}^{\prime}$ describes the anisotropic dipole-dipole interactions between the electron spin $S$ and the nuclear spin $I$. Because the second-rank tensor $\mathbf{A}^{\prime}$ is traceless and symmetric, there is always a coordinate system in which $\mathbf{A}^{\prime}$ is diagonal with the elements $A_{\perp}^{\prime}$ and $A_{\|}^{\prime}=$ $-2 A_{\perp}^{\prime}$ where, by convention, $A_{\|}^{\prime}$ is taken to be the principal value with the largest magnitude.

To transform the spin Hamiltonian parameters into structural information, a point-dipole approximation can be assumed with the dipolar hyperfine coupling constant

$$
A_{\perp}^{\prime}=\frac{\mu_{0}}{4 \pi} \frac{g g_{n} \beta_{e} \beta_{n}}{r^{3} h} .
$$

This equation provides an estimate for the distance $r$ between the paramagnetic $\mathrm{Cu}^{2+}$ center and the coupling ${ }^{1} \mathrm{H}$ nucleus.

By using EPR, oxidation state and site of incorporation of the copper functional center can be obtained. The corresponding FID-induced EPR spectrum is displayed in Figure 1. The axially symmetric $g$-matrix with diagonal elements $g_{\|}$ $=2.332>g_{\perp}=2.049>g_{e}=2.0023$ and ${ }^{63} \mathrm{Cu} A$-hyperfine tensor with diagonal elements ${ }^{63} \mathrm{Cu} A_{\|}=395 \mathrm{MHz}$ and ${ }^{63} \mathrm{Cu}_{\perp}$ $=20 \mathrm{MHz}$ is characteristic for $\mathrm{Cu}^{2+}$-centers in octahedral coordination, distorted along one of the pseudocubic axes. ${ }^{22-24}$ This assignment is in line with recent ab-initio calculations. $^{19}$

Accordingly, the incorporation reaction of $\mathrm{CuO}$, replacing $\mathrm{TiO}_{2}$, is

$$
\mathrm{CuO} \stackrel{\mathrm{TiO}_{2}}{\longrightarrow} \mathrm{Cu}_{\mathrm{Ti}}^{\prime \prime}+\mathrm{O}_{\mathrm{O}}^{\times}+V_{\mathrm{O}}^{*},
$$

where, for charge compensation, each $\mathrm{Cu}_{\mathrm{Ti}}^{\prime \prime}$ is compensated by an oxygen vacancy $\left(V_{\mathrm{O}}^{* *}\right)$ as nearest neighbor, forming a charge neutral $\left(\mathrm{Cu}_{\mathrm{Ti}}^{\prime \prime}-V_{\mathrm{O}}^{* *}\right)^{\times}$defect complex ${ }^{19,25}$

$$
\mathrm{Cu}_{\mathrm{Ti}}^{\prime \prime}+V_{\mathrm{O}}^{\bullet \bullet} \rightleftharpoons\left(\mathrm{Cu}_{\mathrm{Ti}}^{\prime \prime}-V_{\mathrm{O}}^{* \bullet}\right)^{\times} .
$$

Defects that may result from a trapping of conduction electrons, such as singly charged $V_{\mathrm{O}}^{\cdot 27}$ or reduced $\mathrm{Ti}_{\mathrm{Ti}}^{\prime}$-centers, ${ }^{28}$ were not observed.

Considering now the dissolution of hydrogen from either forming-gas atmosphere or from humid conditions into the $\mathrm{PbTiO}_{3}$ lattice, the following dissolution reactions take place:

$$
\begin{aligned}
& \mathrm{H}_{2}(g)+2 \mathrm{O}_{\mathrm{O}}^{\times} \stackrel{\mathrm{PbTiO}_{3}}{\longrightarrow} 2(\mathrm{OH})_{\mathrm{O}}^{\bullet}+2 e^{\prime}, \\
& \mathrm{H}_{2} \mathrm{O}(g)+V_{\mathrm{O}}^{*}+\mathrm{O}_{\mathrm{O}}^{\times} \stackrel{\mathrm{PbTiO}_{3}}{\longrightarrow} 2(\mathrm{OH})_{\mathrm{O}}^{\cdot} .
\end{aligned}
$$

Because in oxidic environments protons cannot substitute other cations and, furthermore, hydrogen interstitials $\left(\mathrm{H}_{i}^{*}\right)$ are always bonded to oxide ions, they will form hydroxide $(\mathrm{OH})_{\mathrm{O}^{-}}^{-}$-complexes. The $[\mathrm{OH}]^{-}$defects in turn are proposed acting as a fixed charged dipole that may pin ferroelectric domain walls. ${ }^{30}$

The existence of hydroxide $(\mathrm{OH})_{\mathrm{O}}^{\circ}$-complexes in perovskite oxides is experimentally supported by findings from barium titanate, where hydrogen atoms act as donor centers, ${ }^{31}$ and where the hydrogen interstitial then combines with an $\mathrm{O}^{2-}$ ion and forms a hydroxide-ion $(\mathrm{OH})_{\mathrm{O}}^{\circ}$, whose existence has been proved by its Raman signature. ${ }^{32,33}$ Electronically, interstitial hydrogen in $\mathrm{PbTiO}_{3}$ was proposed to act as a shallow donor impurity. ${ }^{3}$ Note that as a fundamental difference in the dissolution reactions under forming gas and water vapor conditions, for the latter case the existence of oxygen vacancies describes a necessary prerequisite for the uptake and dissolution of water into the perovskite lattice.

For steric reasons, $(\mathrm{OH})_{\mathrm{O}}^{-}$-defects are expected to be located more likely close to $\mathrm{Cu}_{\mathrm{Ti}}^{\prime \prime}$ rather than $\mathrm{Ti}_{\mathrm{Ti}}^{\times}$-sites. To probe $(\mathrm{OH})_{\mathrm{O}}^{-}$-defects in coordination spheres of the paramagnetic $\mathrm{Cu}_{\mathrm{Ti}}^{\prime \prime}$-site, orientation-selective HYSCORE has been performed. The ${ }^{1} \mathrm{H}-\mathrm{HYSCORE}$ spectrum, taken on an observer position of $278.5 \mathrm{mT}$ that coincides with the $g_{\|}$orientation, is depicted in Figure 2. Assuming the g-matrix main axes being determined by the tetragonal $\mathrm{PbTiO}_{3}$ crystal distortion, the $g_{\|}$-orientation is assumed to be collinear with the orientation of spontaneous polarization, $P_{S} \| g_{\|} \cdot{ }^{17}$

The spectrum is dominated by a correlation that appears as off-diagonal cross-peak ridges shifted by $\Delta \nu_{s}=2.19(5)$ $\mathrm{MHz}$ with respect to the proton nuclear Larmor frequency $\left(\nu_{\mathrm{H}}\right)$, thus showing that the coordinated nuclear spin belongs to a ${ }^{1} \mathrm{H}$-nucleus. To determine the distance between $\mathrm{Cu}_{\mathrm{Ti}}^{\prime \prime}$ and $\mathrm{H}_{i}$, the value for $A_{\perp}^{\prime}$ is estimated from the frequency shift $\Delta \nu_{s}$ as $\left|A_{\perp}^{\prime}\right|=\frac{4}{3}\left(2^{\frac{1}{2}} \nu_{\mathrm{H}} \Delta \nu_{s}\right)^{\frac{1}{2}}=8.08(9) \mathrm{MHz}^{26}$ Adopting the pointdipole approximation (2), the distance between the $\mathrm{Cu}^{2+}$-ion

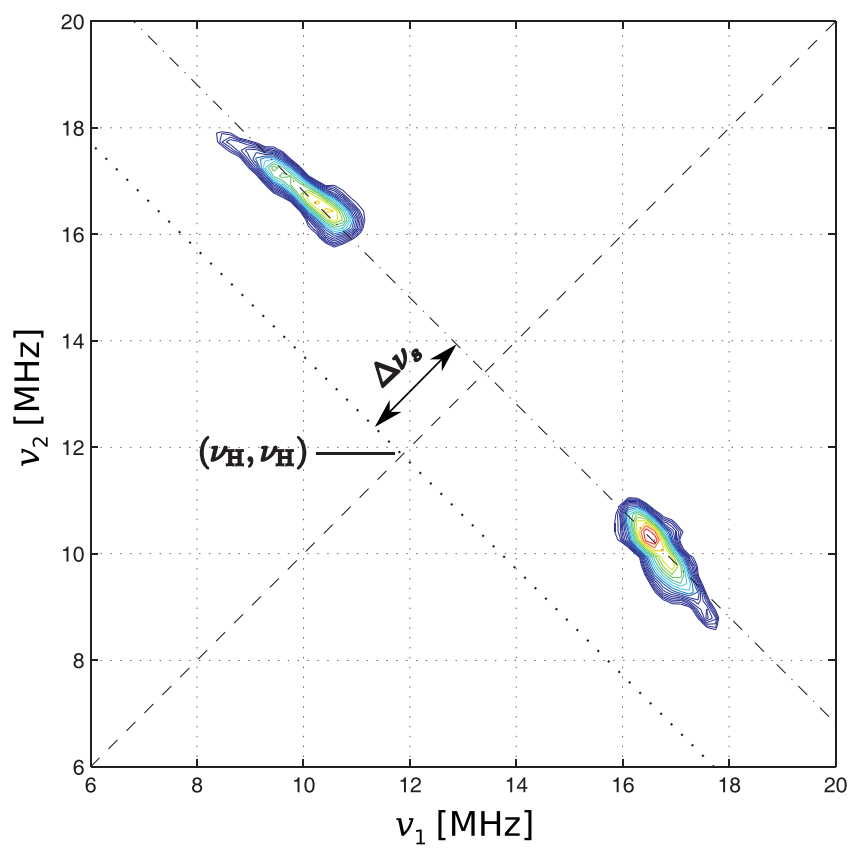

FIG. 2. X-band ${ }^{1} \mathrm{H}$-HYSCORE spectrum (high-frequency part of $(+,+$ ) quadrant) recorded at $10 \mathrm{~K}$ and an observer position of $278.5 \mathrm{mT}$. The dashed lines show the frequency diagonal axis $\nu_{1}=\nu_{2}$; the antidiagonal (dotted line) crosses the diagonal at $\left(\nu_{\mathrm{H}}, \nu_{\mathrm{H}}\right)$. The maximum vertical shift $\Delta \nu_{s}=2.2 \mathrm{MHz}$ of the cross-peak ridges from the antidiagonal is illustrated by a dashed-dotted line. 
and the ${ }^{1} \mathrm{H}$-nucleus is estimated to be 225(2) pm. On the basis of this distance, the above made assumption that the hydroxide defect should form a defect complex with the $\mathrm{Cu}_{\mathrm{Ti}}^{\prime \prime}$-functional center could be validated. The observed coupling is assigned to a ${ }^{1} \mathrm{H}$ nucleus in the first coordination sphere. From the position and shape of the cross-peak ridges, which are approaching the maximum distance from the antidiagonal through point $\left(\nu_{\mathrm{H}}, \nu_{\mathrm{H}}\right)$, it can be inferred that the dipolar interaction is tilted from the direction of spontaneous polarization by approximately $\theta=30(5)^{\circ}$. Based on the distance between $\mathrm{Cu}$ and $\mathrm{O}$ of approximately $223 \mathrm{pm},{ }^{19}$ and the length of a bond between $\mathrm{O}$ and $\mathrm{H}$ in a hydroxide defect of about $98 \mathrm{pm},{ }^{3,29}$ this suggests that the $\mathrm{O}-\mathrm{H}$ bond is approximately perpendicular to the direction of $P_{S}$.

Based on this assignment, the hydrogen dissolution reaction (6) under humid conditions of the "pure" perovskite can be modified for $\mathrm{CuO}$-doped $\mathrm{PbTiO}_{3}$ according to

$$
\begin{aligned}
& \mathrm{H}_{2} \mathrm{O}(g)+\left(\mathrm{Cu}_{\mathrm{Ti}}^{\prime \prime}-V_{\mathrm{O}}^{*}\right)^{\times}+\mathrm{O}_{\mathrm{O}}^{\times} \\
& \stackrel{\mathrm{PbTiO}_{3}}{\longrightarrow}\left(\mathrm{Cu}_{\mathrm{Ti}}^{\prime \prime}-(\mathrm{OH})_{\mathrm{O}}^{\cdot}\right)^{\prime}+(\mathrm{OH})_{\mathrm{O}}^{\cdot},
\end{aligned}
$$

where the oxygen vacancy of the $\left(\mathrm{Cu}_{\mathrm{Ti}}^{\prime \prime}-V_{\mathrm{O}}^{* \bullet}\right)^{\times}$-defect complex is annihilated and replaced by a hydroxide defect, and the two defects formed mutually compensate according to the following charge-neutrality condition:

$$
\left[\left(\mathrm{Cu}_{\mathrm{Ti}}^{\prime \prime}-(\mathrm{OH})_{\mathrm{O}}^{\bullet}\right)^{\prime}\right] \approx\left[(\mathrm{OH})_{\mathrm{O}}^{\bullet}\right] .
$$

Furthermore, the obtained results are in favor of only one well defined site for the hydrogen interstitial adjacent to the $\mathrm{Cu}^{2+}$, because only one set of proton correlation peaks was observed in the ${ }^{1} \mathrm{H}-\mathrm{HYSCORE}$ spectrum (cf. Figure 2). If $\mathrm{H}_{-}^{\circ}$-sites would exist at remote coordination spheres, i.e., neighboring unit cells, additional (weaker) proton hyperfine couplings should exist in the spectrum. The absence of such additional features rules out the existence of additional $(\mathrm{OH})_{\mathrm{O}}{ }^{-}$-defects in the vicinity of the $\mathrm{Cu}_{\mathrm{Ti}}^{\prime \prime}$-functional center. Accordingly, we propose a defect-structural arrangement as schematically illustrated in Figure 3, with the $\left(\mathrm{Cu}_{\mathrm{Ti}}^{\prime \prime}-\right.$ $\left.(\mathrm{OH})_{\mathrm{O}}^{\circ}\right)^{\prime}$ defect complex oriented along the direction of spontaneous polarization.

Considering the reorientation of the $\left(\mathrm{Cu}_{\mathrm{Ti}}^{\prime \prime}-V_{\mathrm{O}}^{*}\right)^{\times}$ defect complex under a sufficiently strong applied external field, an oxygen vacancy has to exchange its position with

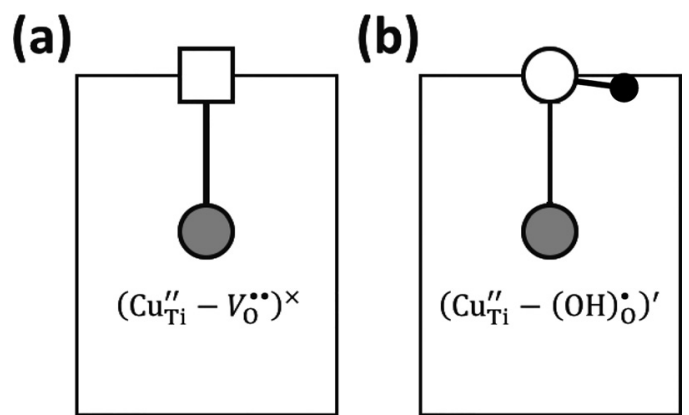

FIG. 3. Schematic illustration of defect structure in $\mathrm{CuO}$-doped $\mathrm{PbTiO}_{3}$ with $\left(\mathrm{Cu}_{\mathrm{Ti}}^{\prime \prime}-V_{\mathrm{O}}^{\bullet}\right)^{\times}$(a) and $\left(\mathrm{Cu}_{\mathrm{Ti}}^{\prime \prime}-(\mathrm{OH})_{\mathrm{O}}^{\bullet}\right)^{\prime}$ (b) defect complexes. The tetragonal unit cell is represented by a bold square, the $\mathrm{Cu}_{\mathrm{Ti}}^{\prime \prime}$-center as a gray circle, the oxygen vacancy $V_{\mathrm{O}}^{*}$ as an open square, an oxygen ion $\mathrm{O}_{\mathrm{O}}^{\times}$as an open circle and the hydrogen interstitial $\mathrm{H}_{i}^{*}$ as a bold circle.
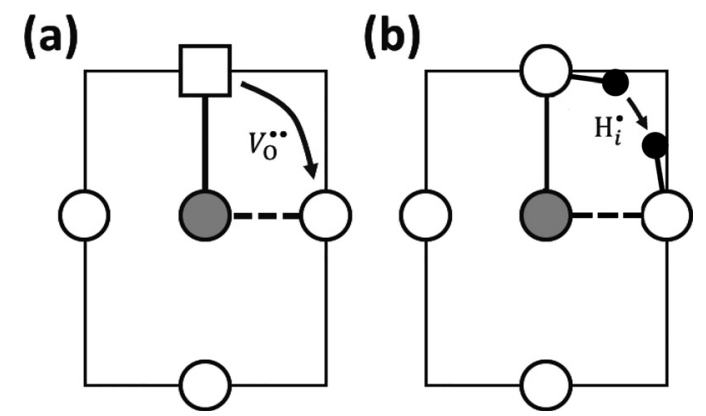

FIG. 4. Schematic illustration of defect-complex reorientation in $\mathrm{CuO}$ doped $\mathrm{PbTiO}_{3}$. (a) Hopping mechanism of an oxygen vacancy $\left(V_{\mathrm{O}}^{*}\right)$ for the reorientation of the $\left(\mathrm{Cu}_{\mathrm{Ti}}^{\prime \prime}-V_{\mathrm{O}}^{*}\right)^{\times}$defect complex. (b) Hopping mechanism of a hydrogen interstitial $\left(\mathrm{H}_{i}^{*}\right)$ for the reorientation of the $\left(\mathrm{Cu}_{\mathrm{Ti}}^{\prime \prime}-(\mathrm{OH})_{\mathrm{O}}^{\circ}\right)^{\prime}$ defect complex.

a lattice oxygen in the first coordination sphere about the $\mathrm{Cu}_{\mathrm{Ti}}^{\prime \prime}$-functional center, ${ }^{13,36-38}$ as schematically illustrated in Figure 4(a). In contrast, reorientation of the $\left(\mathrm{Cu}_{\mathrm{Ti}}^{\prime \prime}-(\mathrm{OH})_{\mathrm{O}}^{\circ}\right)^{\prime}$ defect complex involves a $\mathrm{H}_{i}^{*}$-hopping process from one oxygen site to another oxygen site (cf. Figure 4(b)). The former process involves a hopping of a double charged oxygen ion as compared to the hopping of a singly charged proton for the latter case. Additionally, since $r_{\mathrm{O}^{2-}} \gg r_{\mathrm{H}^{+}}$, the energy needed for the reorientation process will be considerably lower for the $\left(\mathrm{Cu}_{\mathrm{Ti}}^{\prime \prime}-(\mathrm{OH})_{\mathrm{O}}^{\bullet}\right)^{\prime}$ as compared to the $\left(\mathrm{Cu}_{\mathrm{Ti}}^{\prime \prime}-V_{\mathrm{O}}^{\bullet \bullet}\right)^{\times}$defect complex.

The fundamental change in reorientation mechanism, from oxygen-vacancy migration to hydrogen-interstitial hopping, implies a variation of the rate at which defect complexes reorient. The diffusion coefficient of oxygen at ambient temperature is comparatively small (in $\mathrm{BaTiO}_{3}$ at room temperature $D_{\mathrm{O}}=1.1 \times 10^{-15} \mathrm{~cm}^{2} / \mathrm{s}$ ), whereas hydrogen diffusion is $10^{3}$ times as large. ${ }^{7}$ Correspondingly, the variation from $V_{\mathrm{O}^{\circ}}$-migration to $\mathrm{H}_{i}^{*}$-hopping comes along with a markedly reduced activation energy barrier for defect complex reorientation. Tentatively, a reduction in materials "hardening" can be expected from the anticipated variation in defect complex reorientation.

Exploiting the charge neutrality condition (8), in addition to the hydroxide defect forming $\left(\mathrm{Cu}_{\mathrm{Ti}}^{\prime \prime}-(\mathrm{OH})_{\mathrm{O}}^{\circ}\right)^{\prime}$ defect complexes, also hydroxide defects in remote areas to $\left(\mathrm{Cu}_{\mathrm{Ti}}^{\prime \prime}-V_{\mathrm{O}}^{*}\right)^{\times}$defect complexes will be present. These contribute to the electrical conductivity by means of an ionic charge-transport mechanism

$$
(\mathrm{OH})_{\mathrm{O}}^{\bullet}+\mathrm{O}_{\mathrm{O}}^{\times} \rightleftharpoons \mathrm{O}_{\mathrm{O}}^{\times}+(\mathrm{OH})_{\mathrm{O}}^{\bullet},
$$

where the bond of the hydrogen to one lattice oxygen ion is broken and subsequently forming a new bond to a nearest-neighbor lattice oxygen. This so-called "Grotthuss-mechanism" effectively promotes migration of protons in an external field. Although a major pathway of the $\mathrm{H}_{i}^{-}$-diffusion is typically expected along grain boundaries, ${ }^{8}$ the results obtained here demonstrate that hydrogen interstitials also diffuse into the grain core, forming defect complexes.

The impact of local mobility of the protons on the mobility of the dipoles has been discussed in context with Figures 3 and 4 . The lower energy required for the hopping of the protons compared to a hopping of the oxygen vacancies favors 
switching of domains, because non-reorienting dipoles provide no longer an obstacle to domain reorientation. Thus, the proton hopping will result in an enhanced performance with respect to polarization and strain under applied electric fields. However, the overall effects of the presence of protons in the material require a consideration of the long distance mobility as well. A consequence of long range mobility of charge carriers is conductivity. In materials for devices such as capacitors or actuators that should ideally be insulators, conductivity is a loss mechanism which decreases the performance. Moreover, diffusion of charged carriers, such as the protons, over distances of several hundreds of nanometers to domainor grain boundaries may result in internal bias fields by formation of space charges, ${ }^{2,39-41}$ which provide mechanisms for the charge compensation that counteract polarization reversal and induce aging. The presence of protons thus may enhance mobility of domains via reducing the energy required for switching of the dipoles, but most likely will promote pinning effects via the space charge mechanisms.

In summary, the theoretically predicted existence of hydrogen interstitials ${ }^{3}$ has been experimentally proved. In particular, the impact of hydrogen interstitials on the defect structure of $\mathrm{CuO}$-doped $\mathrm{PbTiO}_{3}$ has been characterized. The main experimental observation consists in the formation of $\left(\mathrm{Cu}_{\mathrm{Ti}}^{\prime \prime}\right.$ $\left.-(\mathrm{OH})_{\mathrm{O}}^{\bullet}\right)^{\prime}$ defect complexes that exist in addition to the $\left(\mathrm{Cu}_{\mathrm{Ti}}^{\prime \prime}-V_{\mathrm{O}}^{\bullet \bullet}\right)^{\times}$complexes. Compared to $\left(\mathrm{Cu}_{\mathrm{Ti}}^{\prime \prime}-V_{\mathrm{O}}^{\bullet}\right)^{\times}$complexes, modified reorientation characteristics are proposed due to a change in hopping mechanism from an oxygenvacancy mediated migration mechanism to a proton hopping process. Second, exploiting the charge-neutrality condition (8), only half of the hydrogen interstitials form $\left(\mathrm{Cu}_{\mathrm{Ti}}^{\prime \prime}-\right.$ $\left.(\mathrm{OH})_{\mathrm{O}}\right)^{\prime}$ defect complexes, and the remaining part generates mobile hydrogen interstitials according to a "Grotthuss"-type charge-transport mechanism that impacts the conductivity of the material and could explain the observed transition from a ferroelectric insulating, to a semi-conducting compound.

Tentatively, both mechanisms are expected to affect the ferroelectric properties. These properties are usually discussed in terms of interactions with domain walls. ${ }^{34-36}$ Corresponding interpretations have been suggested and a significant impact can be expected, which should be investigated in more detail.

${ }^{1}$ R.-A. Eichel, H. Kungl, and P. Jakes, Mater. Technol. 28, 241-246 (2013). ${ }^{2}$ Y. A. Genenko, J. Glaum, M. J. Hoffmann, and K. Albe, Mater. Sci. Eng. 192, 52-82 (2015).

${ }^{3}$ C. H. Park and D. J. Chadi, Phys. Rev. Lett. 84, 4717 (2000).

${ }^{4}$ Y. Shimamoto, K. Kushida-Abdelghafar, H. Miki, and Y. Fujisaki, Appl. Phys. Lett. 70, 3096 (1997).

${ }^{5}$ J. P. Han and T. P. Ma, Appl. Phys. Lett. 71, 1267 (1997).

${ }^{6}$ H. J. Joo, S. H. Lee, J. P. Kim, M. K. Ryu, and M. S. Jang, Ferroelectrics 272, 149-154 (2002).
${ }^{7}$ H. Y. Huang, W. Y. Chu, Y. T. Su, K. W. Gao, J. X. Li, and L. J. Qiao, J. Am. Ceram. Soc. 90, 2062-2066 (2007).

${ }^{8}$ N. J. Donnelly and C. A. Randall, J. Am. Ceram. Soc. 92, 405-410 (2009).

${ }^{9}$ I. P. Lipscombe, P. M. Weaver, J. Swingler, and J. W. McBride, Sens. Actuators, A 151, 179-186 (2009).

${ }^{10}$ M. Wu, H. Y. Huang, W. Y. Chu, L. Q. Guo, L. J. Qiao, J. Y. Xu, and T. Y. Zhang, J. Phys. Chem. C 114, 9955-9960 (2010).

${ }^{11}$ F. Chen, W. P. Chen, Y. Wang, Y. M. Hu, Z. J. Shen, and H. L. W. Chan, Physica B 406, 683-686 (2011).

${ }^{12}$ R.-A. Eichel, Phys. Chem. Chem. Phys. 13, 368-384 (2011).

${ }^{13}$ P. Jakes, H. Kungl, R. Schierholz, and R.-A. Eichel, IEEE Trans. Ultrason. Ferroelectr. Freq. Control 61, 1447-1455 (2014).

${ }^{14}$ E. Erünal, P. Jakes, S. Körbel, J. Acker, H. Kungl, C. Elsässer, M. J. Hoffmann, and R.-A. Eichel, Phys. Rev. B 84, 184113 (2011).

${ }^{15}$ E. Erdem, P. Jakes, S. K. S. Parashar, K. Kiraz, M. Somer, A. Rüdiger, and R.-A. Eichel, J. Phys.: Condens. Matter 22, 345901 (2010).

${ }^{16}$ E. Erünal, R.-A. Eichel, S. Körbel, C. Elsässer, J. Acker, H. Kungl, and M. J. Hoffmann, Funct. Mater. Lett. 3, 19-24 (2010).

${ }^{17}$ R.-A. Eichel, H. Mestric, K. P. Dinse, A. Ozarowski, J. van Tol, L. C. Brunel, H. Kungl, and M. J. Hoffmann, Magn. Reson. Chem. 43, S166-S173 (2005).

${ }^{18}$ R.-A. Eichel, K.-P. Dinse, H. Kungl, M. J. Hoffmann, A. Ozarowski, J. van Tol, and L. C. Brunel, Appl. Phys. A 80, 51-54 (2005).

${ }^{19}$ R.-A. Eichel, P. Erhart, P. Träskelin, K. Albe, H. Kungl, and M. J. Hoffmann, Phys. Rev. Lett. 100, 095504 (2008).

${ }^{20}$ R.-A. Eichel, H. Kungl, and M. J. Hoffmann, J. Appl. Phys. 95, 8092-8096 (2004).

${ }^{21}$ C. Gemperle, G. Aebli, A. Schweiger, and R. R. Ernst, J. Magn. Reson. 88, 241 (1990).

${ }^{22}$ W. L. Warren, B. A. Tuttle, F. C. Rong, G. J. Gerardi, and E. H. Poindexter, J. Am. Ceram. Soc. 80, 680 (1997).

${ }^{23}$ H. T. Langhammer, T. Müller, R. Böttcher, and H.-P. Abicht, Solid State Sci. 5, 965 (2003).

${ }^{24}$ R.-A. Eichel, E. Erünal, M. D. Drahus, D. M. Smyth, J. van Tol, J. Acker, H. Kungl, and M. J. Hoffmann, Phys. Chem. Chem. Phys. 11, 8698-8705 (2009).

${ }^{25}$ R.-A. Eichel, M. D. Drahus, P. Jakes, E. Erünal, E. Erdem, S. K. S, Parashar, H. Kungl, and M. J. Hoffmann, Mol. Phys. 107, 1981-1986 (2009).

${ }^{26}$ A. Pöppl and L. Kevan, J. Phys. Chem. 100, 3387 (1996).

${ }^{27}$ R.-A. Eichel, E. Erdem, P. Jakes, A. Ozarowski, J. van Tol, R. Hoffmann, and J. J. Schneider, Funct. Mater. Lett. 6, 1330004 (2013).

${ }^{28}$ E. Erdem, P. Jakes, R.-A. Eichel, D. C. Sinclair, M. Pasha, and I. M. Reaney, Funct. Mater. Lett. 3, 65-68 (2010).

${ }^{29}$ K. Xiong and J. Robertson, Appl. Phys. Lett. 85, 2577-2579 (2004).

${ }^{30}$ D. Dimos, W. L. Warren, M. B. Sinclair, B. A. Tuttle, and R. W. Schwartz, J. Appl. Phys. 76, 4305 (1994).

${ }^{31}$ R. Waser, J. Am. Ceram. Soc. 71, 58 (1988).

${ }^{32}$ S. Kapphan and G. Weber, Ferroelectrics 37, 673-676 (1981).

${ }^{33}$ S. Aggarwal, S. R. Perusse, C. W. Tipton, R. Ramesh, H. D. Drew, T. Venkatesan, D. B. Romero, V. B. Podoedov, and A. Weber, Appl. Phys. Lett. 73, 1973-1975 (1998).

${ }^{34}$ P. V. Lambeck and G. H. Jonker, J. Phys. Chem. Solids 47, 453 (1986).

${ }^{35}$ H. Neumann and G. Arlt, Ferroelectrics 76, 303 (1987).

${ }^{36}$ R.-A. Eichel, E. Erünal, P. Jakes, S. Körbel, C. Elsässer, H. Kungl, J. Acker, and M. J. Hoffmann, Appl. Phys. Lett. 102, 242908 (2013).

${ }^{37}$ W. L. Warren, K. Vanheusden, D. Dimos, G. E. Pike, and B. A. Tuttle, J. Am. Ceram. Soc. 79, 536 (1996).

${ }^{38}$ L. X. Zhang, E. Erdem, X. Ren, and R.-A. Eichel, Appl. Phys. Lett. 93, 202901 (2008).

${ }^{39}$ G. Arlt and H. Neumann, Ferroelectrics 87, 109-120 (1988).

${ }^{40}$ K. Carl and K. H. Härdtl, Ferroelectrics 17, 473-486 (1978).

${ }^{41}$ Y. A. Genenko, Phys. Rev. B 78, 214103 (2008). 